Gut, 1968, 9, 373-375

\title{
Gastric intrinsic factor
}

The demonstration, by W. B. Castle ${ }^{1}$ and his collaboraters some 40 years ago of a haemopoietic substance in the gastric secretion absent in pernicious anaemia was the starting point of a chain of observations that has continued to the present time.

Intrinsic factor (IF) has now been obtained in a relatively pure state from human gastric juice ${ }^{2}$ and from hog pyloric mucosa. ${ }^{3}$ It is a mucoprotein with a molecular weight of about 60,000 and contains about $13 \%$ of carbohydrates. Each molecule binds one molecule of vitamin $B_{12}$, that is, $1 \mathrm{mg}$ of IF binds $25 \mu \mathrm{g}$ of vitamin $B_{12}$. In man, as well as in the guinea pig, cat, rabbit, and monkey, IF arises from the gastric parietal cell but surprisingly in the rat and mouse its source is the chief cell. ${ }^{4}$ Substances that stimulate secretion of hydrochloric acid in man also stimulate that of intrinsic factor. These include histamine and gastrin and their analogues, and insulin. Cholinergic drugs such as carbachol are not effective. ${ }^{5,6}$ The early and rapid rise in intrinsic factor secretion preceding that of acid has suggested that the stimulus to secretion has washed out preformed IF from the parietal cell. If, however, histamine is infused over a longer period the IF level is maintained above base line levels indicating a continuous stimulus to increased production. ${ }^{7}$

The normal stomach produces far more intrinsic factor than is required for vitamin $B_{12}$ absorption. Indeed, only about $1 \%$ of the normal daily output is required to achieve maximum absorption of a $1.0 \mu \mathrm{g}$ dose of vitamin $\mathbf{B}_{12}{ }^{5}$ Impaired vitamin $B_{12}$ absorption implies loss of at least $99 \%$ of IF secreting capacity.

The large excess of intrinsic factor that is available under normal circumstances implies that stimulants to gastric secretion are not likely to influence vitamin $B_{12}$ absorption. The exception to this rule probably occurs after partial gastrectomy. Deller et al $(1961)^{8}$ first pointed out that there was a significant increase in the amount of vitamin $B_{12}$ absorbed after partial gastrectomy when the $\mathrm{B}_{12}$ was given with a meal rather than in the fasting state. This was confirmed by Turnbull $(1967)^{9}$, who also noted that a similar increment in absorption took place when histamine (40 $\mu \mathrm{g}$ per $\mathrm{kg}$ ) was substituted for the meal. This suggests that after gastrectomy a stimulus is required to produce adequate IF from the gastric remnant. Rune (1966) ${ }^{\mathbf{1 0}}$ has suggested that food has an effect on gastric secretion similar to that of an augmented dose of histamine. In the light of these observations it is necessary to re-examine $B_{12}$ absorption in post-gastrectomy patients. The frequency of $B_{12}$ malabsorption after partial gastrectomy when the test is performed in the fasting state is $30 \%{ }^{11}$ This may prove to be too high an estimate, particularly when the frequency of megaloblastic anaemia due to vitamin $B_{12}$ deficiency in this group is likely to be of the order of 5 to $6 \%{ }^{12}$

The production of IF may be suppressed by IF antibody. This antibody also prevents the attachment of vitamin $B_{12}$ to IF, presumably by combining with the vitamin $\mathrm{B}_{12}$-binding site. Both Bar-Shany and Herbert (1967) ${ }^{13}$ and Goldberg et al (1967) ${ }^{14}$ studied infants born to mothers with pernicious anaemia. Intrinsic factor antibody had crossed the placenta and was present 
in the infant's serum, and, in one child, in the gastric secretion. Intrinsic factor could not be demonstrated in the gastric juice of either of these infants till about 1 to 3 months of age when IF-antibody had largely disappeared. Thereafter IF appeared in the gastric juice in normal amount. Intrinsic factor is always present in gastric secretion collected on the first day of life from normal infants. This mechanism may be important in pernicious anaemia and suppression of such antibody may, in part, account for the improvement in vitamin $\mathbf{B}_{12}$ absorption in steroid-treated pernicious anaemia patients.

Most of the vitamin $B_{12}$ present in food is available for absorption ${ }^{15}$. Intrinsic factor binds firmly and rapidly to dietary vitamin $\mathrm{B}_{12}$. In vitro the reaction between IF and $\mathrm{B}_{12}$ in solution is complete in a few seconds. In vivo much of the reaction occurs in the stomach but can also take place in the gut. ${ }^{16,17}$ Like all biochemical reactions an equilibrium is achieved between free IF, free $B_{12}$, and the complex and indeed IF-bound $B_{12}$ readily exchanges with labelled vitamin $B_{12}$ in the environment. ${ }^{18}$ The reaction is unaffected by change in $p \mathrm{H}$ and once bound to vitamin $\mathrm{B}_{12}$ IF becomes relatively resistant to proteolytic digestion. ${ }^{19}$ This is particularly important because the complex must survive exposure to proteolytic enzymes in its long passage to the ileum.

Some intrinsic factor normally persists in the small gut probably adsorbed on the villous cells. Total gastrectomy in the rat is not followed by an abrupt cessation of vitamin $\mathrm{B}_{12}$ absorption but by a gradual decline over 24 hours. ${ }^{20}$ Booth et al (1957), ${ }^{21}$ in their study of vitamin $B_{12}$ absorption in rats, demonstrated transient uptake of some vitamin $B_{12}$ presumably bound to intrinsic factor in the upper gut and a return of this material to the lumen to be reattached lower down the gut. This phenomenon occurs in man, and vitamin $\mathrm{B}_{12}$ attachment to jejunum was demonstrated by Doscherholmen et al (1960) ${ }^{22}$ in one patient who died two hours after taking an oral dose of labelled vitamin $B_{12}$. This transient binding of $I F-B_{12}$ to jejunum is also the explanation of the observation of Gazet and McColl (1967) ${ }^{23}$ that vitamin $B_{12}$ introduced to an isolated jejunal loop at operation was partially retained there. However, absorption of vitamin $B_{12}$ does not take place from the jejunum even when left in that site for up to 12 hours. ${ }^{24}$ Absorption only follows the release of vitamin $B_{12}$ to the lumen and its reattachment lower down the gut.

The large body of evidence on the effect of small gut resection on vitamin $B_{12}$ absorption points unequivocally to the ileum as the only site of IFmediated $\mathrm{B}_{12}$ absorption in man. ${ }^{25,26,27,28}$

Once the ileum is reached the fate of IF is less certain. The complex attaches to 'receptors' on the brush borders and microvillous membranes of the cells lining the villi. ${ }^{29}$ That there are specific receptors for attachment of IF- $B_{12}$ in the ileum is implied in the fact that only this particular segment of gut is capable of vitamin $B_{12}$ absorption, that the amount of vitamin $B_{12}$ that can be absorbed at one time through the agency of intrinsic factor is strictly limited to about $2.0 \mu \mathrm{g}$, and, most important, ileal absorption of vitamin $\mathbf{B}_{12}$ may fail as an isolated gut abnormality in congenital vitamin $B_{12}$ malabsorption (Gräsbeck-Imerslund), a disorder transmitted as a recessive characteristic. This disorder is associated with albuminuria and suggests a failure of protein transport across a membrane involving both villous cell and renal tubule. This, indeed, is the only evidence that IF- $\mathrm{B}_{12}$ may enter the villous cell. 
Thereafter our information about IF is even less certain. It is likely that there is slow separation of IF from $B_{12}$ so that the latter reaches the portal blood in highest amount only some eight to 12 hours after the oral dose. ${ }^{30}$ That IF is left behind is suggested by normal vitamin $B_{12}$ absorption in a small group of otherwise healthy thyroid patients who have IF antibodies in serum, and by the failure to identify IF after cannulation of both lymphatics and portal blood during $\mathrm{B}_{12}$ absorption. ${ }^{31,32}$

\section{REFERENCES}

I. CHANARIN

${ }^{1}$ Castle, W. B., and Townsend, W. C. (1929). Observations on the etiologic relationship of achylia gastrica to pernicious anemia. II. The effect of the administration to patients with pernicious anemia of beef muscle after incubation with normal human gastric juice. Amer. J. med. Sci., 178, 764-777.

${ }^{2}$ Gräsbeck, R., Simons, K., and Sinkkonen, I. (1966). Isolation of intrinsic factor and its probable degradation product as their vitamin $B_{12}$ complexes, from human gastric juice. Biochim. biophys. Acta (Amst.), $127,47-58$.

${ }^{3}$ Ellenbogen, L., and Highley, D. R. (1967). Hog intrinsic factor. I. Isolation of vitamin $\mathbf{B}_{12}$-binding fractions from hog pylorus. J. biol. Chem., 242, 1004-1009.

'Hoedemaeker, P. J., Abels, J., Wachters, J. J., Arends, A., and Nieweg, H. O. (1964). Investigations about the site of production of Castle's gastric intrinsic factor. Lab. Invest., 13, 1394-1399.

${ }^{5}$ Ardeman, S., Chanarin, I., and Doyle, J. C. (1964). Studies on secretion of gastric intrinsic factor in man. Brit. med. J., 2, 600-603.

- - - - (1965). Stimulation of gastric intrinsic factor secretion. Brit. med. J., 1, 1417-1418.

${ }^{7}$ Weir, D. G., Temperley, I. J., and Collery, D. (1967). Intrinsic factor secretion in response to continuous histamine infusion. Gastroenterology, 52, 23-28.

${ }^{8}$ Deller, D. J., Germar, H., and Witts, L. J. (1961). Effect of food on absorption of radioactive vitamin $B_{12}$. Lancet, 1, 574-577.

'Turnbull, A. L. (1967). Absorption of vitamin $B_{12}$ in patients with anaemia after polya partial gastrectomy. Brit. J. Haemat., 13, 752-763.

${ }^{10}$ Rune, S. J. (1966). Comparison of the rates of gastric acid secretion in man after ingestion of food and after maximal stimulation with histamine. Gut, 7, 344-350.

${ }^{11}$ Lous, P., and Schwartz, M. (1959). The absorption of vitamin $\mathbf{B}_{12}$ following partial gastrectomy. Acta med. Scand. 164, 407-417.

${ }^{12}$ Deller, D. J., and Witts, L. J. (1962). Changes in the blood after partial gastrectomy with special reference to vitamin $B_{12}$. I. Serum vitamin $B_{12}$ haemoglobin, serum iron, and bone marrow. Quart. J. med., 31, 71-102.

${ }^{13}$ Bar-Shany, S., and Herbert, Y. (1967). Transplacentally acquired antibody to intrinsic factor with vitamin $\mathrm{B}_{12}$ deficiency. Blood, 30, 777-784.

${ }^{14}$ Goldberg, L. S., Barnett, E. V., and Desai, R. (1967). Effect of transplacental transfer of antibody to intrinsic factor. Pediatrics, 40, 851-855.

${ }^{15}$ Heyssell, R. M., Bozian, R. C., Darby, W. C., and Bull, M. C. (1966). Vitamin $B_{12}$ turnover in man. The assimilation of vitamin $\mathbf{B}_{12}$ from natural foodstuffs by man and estimates of minimal daily dietary requirements. Amer. J. clin. Nutr., 18, 176-184.

${ }^{16}$ Latner, A. L. (1959). Observations related to the role of intrinsic factor in intestinal vitamin $B_{12}$ absorption. Haemat. lat. (Milano), 2, 209-213.

${ }^{17}$ Highley, D. R., and Ellenbogen, L. (1962). Studies on the mechanism of vitamin $\mathbf{B}_{12}$ absorption: in vivo transfer of vitamin $B_{1,}$ to intrinsic factor. Arch. Biochem., 99, 126-131.

${ }^{18}$ Donaldson, R. M., Jr, and Katz, J. H. (1963). Exchange between free and gastric juice-bound cyanocobalamin. J. clin. Invest., 42, 534-545.

${ }^{19}$ Abels, J., and Schilling, R. F. (1964). Protection of intrinsic factor by vitamin B ${ }_{19}$. J. Lab. clin. Med., 64, 375-384.

${ }^{20} \mathrm{~J}$ ohnson, P. C., and Driscoll, T. B. (1962). Interrelationship of intrinsic factor and bile to the absorption and distribution of vitamin $B_{12}$. In Vitamin $B_{12}$ und Intrinsic Factor, 2nd Europ. Symposium, Hamburg, pp. 534-539. Edited by H. C. Heinrich. F. Enke, Stuttgart.

${ }^{21}$ Booth, C. C., Chanarin, I., Anderson, B. B., and Mollin, D. L. (1957). The site of absorption and tissue distribution of orally administered ${ }^{58} \mathrm{Co}-$ labelled vitamin $\mathbf{B}_{12}$ in the rat. Brit. J. Haemat., 3, 253-261.

${ }^{22}$ Doscherholmen, A., Finley, P. R., and Hagen, P. S. (1960). Distribution of radioactivity in man after the oral ingestion of small test doses of radiolabeled cyanocobalamin. J. Lab. clin. med., 56, 547-554.

${ }^{28}$ Gazet, J. C., and McColl, I. (1967). Absorption of vitamin $B_{18}$ from the small intestine. Study in man, monkey, cat and dog. Brit. J. Surg., 54, 128-131.

${ }^{24}$ Best, W. R., Frenster, J. H., and Zolot, M. M. (1957). Observations on intrinsic factor and the intestinal absorption of Vitamin B. J. Lab. clin. Med., 50, 793.

${ }^{25}$ McIntyre, P. A., Sachs, M. V., Krevans, J. R., and Conley, C. L. (1956). Pathogenesis and treatment of macrocytic anemia. Arch. Intern. Med., 98, 541-549.

${ }^{26}$ Booth, C. C., and Mollin, D. L. (1957). Importance of the ileum in the absorption of vitamin $\mathbf{B}_{12}$. Lancet,

$27,2,1007$.

${ }^{28}$ Cox, E. V., Meynell, M. J., Cooke, W. T., and Gaddie, R. (1958). The folic acid excretion test in the steatorrhea syndrome. Gastroenterology, 35, 390-397.

${ }^{20}$ Donaldson, R. M., Jr, Mackenzie, I. L., and Trier, J. S. (1967). Intrinsic factor-mediated attachment of vitamin $B_{12}$ to brush borders and microvillous membranes of hamster intestine. J. clin. Invest., 46, 1215 1228.

${ }^{30}$ Booth, C. C., and Mollin, D. L. (1956). Plasma, tissue and urinary radioactivity after oral administration of

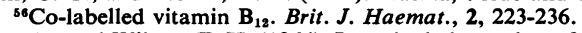

${ }^{31}$ Boass, A., and Wilson, T. H. (1964). Intestinal absorption of intrinsic factor and $\mathbf{B}_{12}$-intrinsic factor complex. Amer. J. Physiol., 207, 27-32.

${ }^{32}$ Cooper, B. A., and White, J. J. (1968). Absence of intrinsic factor from human portal plasma during ${ }^{57} \mathrm{CoB}_{13}$ absorption in man. Brit. J. Haemat., 14, 73-78. 